\title{
Description of Erwiniinae, new subfamily of Dryinidae from Ecuador (Hymenoptera: Chrysidoidea)
}

\author{
MASSIMO OLMI \& ADALGISA GUGLIELMINO ${ }^{1}$
}

Department of Plant Protection, University of Tuscia, Via San Camillo de Lellis, I-01100 Viterbo, Italy. E-mail: olmi@unitus.it ${ }^{1}$ Corresponding author. E-mail: guglielm@unitus.it

\begin{abstract}
Erwiniinae, a new subfamily of Dryinidae, based on Erwinius prognatus, new genus and a new species is described from Ecuador, Napo Province. A new key to subfamilies of Dryinidae is presented.
\end{abstract}

Key words: Erwinius prognatus, new genus, new species, Neotropical, key

\section{Introduction}

Dryinidae (Hymenoptera Chrysidoidea) includes 12 subfamilies (Aphelopinae, Anteoninae, Apoaphelopinae, Apodryininae, Bocchinae, Conganteoninae, Dryininae, Gonatopodinae, Palaeoanteoninae, Plesiodryininae, Ponomarenkoinae, Transdryininae)(Olmi 1984, 1999, 2010). Females have chelate fore legs in all subfamilies, except Aphelopinae.

Aphelopinae includes two genera. Aphelopus Dalman is widely spread throughout all zoogeographic regions, while Crovettia Olmi is known from the Australian, Nearctic, Neotropical and Oriental regions only (Olmi 1984).

The hosts of Aphelopinae are Cicadellidae Typhlocybinae (for Aphelopus) and Membracidae (for Crovettia) (Guglielmino \& Olmi 1997, 2006, 2007). The biologies of the above two genera are diagnostic. Crovettia larvae are completely endophagous and poliembryonic, whereas Aphelopus larvae are initially endophagous and afterwards ectophagous. Aphelopinae larvae are different from all other dryinids, whose larvae are completely ectophagous (Olmi 1994, 1999).

In 1994 three female specimens of Dryinidae without chelae were collected in Ecuador by Dr. Terry L. Erwin. They have peculiar morphologic characters and have been determined to belong not only to a new genus and species, but also to a new subfamily described as follows.

\section{Material and methods}

The descriptions follow the terminology used by Olmi $(1984,1994,1999)$.

The measurements reported are relative, except for the total length (head to abdominal tip, without the antennae), which is expressed in millimetres.

In the descriptions POL is the distance between the inner edges of the two lateral ocelli; OL is the distance between the inner edges of a lateral ocellus and the median ocellus; OOL is the distance from the outer edge of a lateral ocellus to the compound eye; OPL is the distance from the posterior edge of a lateral ocellus to the occipital carina; TL is the distance from the posterior edge of a eye to the occipital carina.

The material studied in this paper is deposited in the following collections: 